\title{
Experimental Analysis on the Effect of Area of Surface Cooling for a Water-Cooled Photovoltaic
}

\author{
Firdaus Basrawi ${ }^{1, *}$, Yeong C. Leon ${ }^{1}$, Thamir K. Ibrahim ${ }^{1,2}$ Mohd Hazwan Yusof ${ }^{1}$, A. A. \\ Razak $^{3}$, Shaharin Anuar Sulaiman ${ }^{4}$ and Takanobu Yamada ${ }^{5}$ \\ ${ }^{1}$ Energy Sustainability Focus Group (ESFG), Faculty of Mechanical Engineering, Universiti \\ Malaysia Pahang, 26600 Pekan, Pahang, Malaysia. \\ ${ }^{2}$ Department of Mechanical Engineering, College of Applied Engineering, University of Tikrit, Tikrit, \\ Iraq \\ ${ }^{3}$ Faculty of Engineering Technology, Universiti Malaysia Pahang, Lebuhraya Tun Razak, 26300 \\ Gambang, Pahang, Malaysia. \\ ${ }^{4}$ Department of Mechanical Engineering, Universiti Teknologi PETRONAS, 32610 Seri Iskandar, \\ Malaysia \\ ${ }^{4}$ Department of Mechanical Engineering, Universiti Teknologi PETRONAS, 32610 Seri Iskandar, \\ Malaysia
}

\begin{abstract}
Water flow for a water-cooled Photovoltaic (PV) may not cover the whole surface area of PV. Thus, the objective of this paper is to experimentally observe the effect of cooling surface area for a water-cooled PV. A water-cooled PV with $30 \mathrm{~W}$ output was tested when its surface area was $50 \%$ and $100 \%$ covered with flowing water. This condition was tested at water flow rate of $120 \mathrm{~mL} / \mathrm{h}$, and irradiace of $855 \mathrm{~W} / \mathrm{m}^{2}$, respectively. It was found that the panel recorded a maximum temperature of $72.10^{\circ} \mathrm{C}$ when it is uncooled. When it is cooled temperature decreased $22.05 \%$ and $51.04 \%$ for half and full surface, respectively, and temperature also remained constant approximately at $32^{\circ} \mathrm{C}$ for full surface. The current remained constant as expected and effect of temperature could be seen in voltage. Voltage increases when temperate decreases, and decreases when temperature increases. As the results, the power outputs for uncooled, half surface, and full surface were $10.38 \mathrm{~W}, 10.66 \mathrm{~W}$ and $11.08 \mathrm{~W}$, respectively. As compared to uncooled, this shows the increment of $6.10 \%$ and $13.50 \%$ for half surface and full surface, respectively. Thus, it could be concluded that the cooling surface area has substantial effects on the performance of water-cooled PV.
\end{abstract}

\section{Introduction}

Photovoltaic (PV) is one of the most popular renewable energy technology in the world with worldwide installed capacity reaching $303 \mathrm{GW}$ by the end of 2016 [1]. In China, the total installed capacity is $78 \mathrm{GW}$ followed by Japan at $42.8 \mathrm{GW}$ and then Germany at 41.2 GW [1]. Malaysia is aiming to achieve up to $1.25 \mathrm{GW}$ worth of grid-connected PV capacity by 2020 [2]. However, such capacity is rated at Standard Test Conditions (STC) and the

*Corresponding author: mfirdausb@ump.edu.my 
actual power generation will be less than that as factors including irradiance and ambient temperature vary from day to day. Temperature is one of the major factors that contributes up to $17.5 \%$ efficiency loss in polycrystalline silicon PV module when the panel temperature exceeds $60^{\circ} \mathrm{C}$ [3], [4], [5]. Thus, there are many methods studied by various researchers to cool down the PV panels. One of the many methods being used is by using water. By spraying water or allowing it to flow on top of the panel, it allowed direct heat transfer and provides cooling through evaporation.

There are many studies reported on the water-cooled PV. Abdolzadeh and Ameri investigated the effect of spraying water over PV cells to reduce cell's temperature and reflection. At $50 \mathrm{~L} / \mathrm{h}$, The total efficiency increased by $1.35 \%$ after considering pump power consumption, and the optical performance also increased by $1.8 \%$ [6]. Niz etic ${ }^{-}$et al. proposed an alternative cooling system whereby the panel is cooled by water spraying at both, the front and back of the panel. At $225 \mathrm{~L} / \mathrm{h}$, the power output for front cooling, back cooling and simultaneous cooling increased 5.4\%, 6.0\%, and 7.7\% respectively [7]. Kordzadeh investigated the effect of nominal power for an array of PV by using thin film of water to cool down the panels. At $40 \mathrm{~L} / \mathrm{h}$, it was found that $3.66 \%$ of efficiency improvement for a 90W (45W x 2 panels) setup using thin film [3]. Similar study by Krauter shows 8-9\% of net electrical gain is possible when using a thin film of water [8]. Another similar study was reported by Dorobantu and Octavian by using thin film of water to increase panel efficiency as well as cleaning it. Power output increased by $9.5 \%$ with water flow capped at $119 \mathrm{~L} / \mathrm{h}$ [9]. Similar approached was investigated by M. K. Smith et al. studied on the cooling and cleaning methods by using uniform thin film of water that is constantly recirculating by pumping over the surface of the PV panel. Net energy improvement considering pump power consumption is at $8.3 \%$ with water flow rate of $7 \mathrm{~L} / \mathrm{min}$ [10]. Moharram et al. also tried to optimize amount of water used and efficiency increment by setting different maximum allowable temperatures (MAT) in his experimental. Water is allowed to flow at a controlled rate of $29 \mathrm{~L} / \mathrm{min}$ and it was found that MAT of $45^{\circ} \mathrm{C}$ is the optimum value to cool the PV [11]. S. Odeh and M. Behnia wanted to apply PV water cooling via an irrigation system for urban and remote site where water pumping from well is required. In their own experiment, cool water at $4 \mathrm{~L} / \mathrm{min}$ is trickled down onto the panel from 32 holes of $5 \mathrm{~mm}$ diameter causing a decrease of $26^{\circ} \mathrm{C}$ and a surplus in power of about 15\% [12]. In a study by Irwan et al., they discussed on the how to increase the electrical efficiency of the photovoltaics panel in indoor test. Water is sprayed on top of the panel and there is a $22.81 \%$ maximum power output increment at $1016 \mathrm{~W} / \mathrm{m}^{2}$ irradiance [13].

However, there is no study reported on the cooling surface area on the total efficiency increase of the PV. Higher surface area covered may not yield significantly higher panel efficiency and the use of additional water to cover more surface area may not be required. This is because in countries where water is precious, the little performance gain by using more water to flow on top of the panel may not be desirable. Thus, the objective of this paper is to investigate the effect of cooling surface area on the performance of a PV.

\section{Materials and methods}

The PV panel was connected to two power resistors rated at $50 \mathrm{~W} 15 \Omega$ each and were connected in series and thus, the total resistance in the circuit was $30 \Omega$. The voltages and current values were recorded and logged using a Fluke 317 Clampmeter and Lutron CM9930 connected with Lutron DL-9602SD. The temperature values were measured using multiple K-type thermocouples and logged using Lutron BTM-4208SD at different locations. Water is pumped using a $10 \mathrm{~W}$ submersible pump and the water flow rate was measured using an YF-S201 flow meter with the data being transmitted to the laptop by using an Arduino Uno. Water flow rate was controller by using a hand valve. Water that flowed on top of the 
panel was recirculated back to the reservoir before being pumped again to cool the panel by using pipes. To create the half and full area cooling effect, two pipes with different span of holes were used. Average irradiance values were measured using a Daystar DA-05A across six different positions under the solar simulator at the same orientation of the PV panel.

The PV panel was tested under the solar simulator with four irradiance values at 855 $\mathrm{W} / \mathrm{m}^{2}$. With each irradiance setting, there were five variables being tested and the data were recorded and analysed. Firstly, the PV panel was exposed to the solar simulator without any cooling being done. Next, the PV panel was subjected to half area cooling using water with two different water flow rate. Finally, the panel was cooled on its entire surface area, also with two different water flow rates that is similar with previous experiment. Table 1 shows the testing conditions for each irradiance value and Table 2 shows the characteristics of the PV panel used. Water flow rates were chosen to be flowing at $120 \mathrm{~L} / \mathrm{h}$ because that is within the range of flow rates being used by other researchers. It is also within the capabilities and limits of the submersible water pump that was used in our experiment.

Table 1. Testing conditions of the PV

\begin{tabular}{|c|c|}
\hline Irradiance value $\left(\mathbf{W} / \mathbf{m}^{2}\right)$ & $\mathbf{8 5 5}$ \\
\hline \multirow{2}{*}{ Testing conditions } & Uncooled, $120 \mathrm{~L} / \mathrm{h}$ \\
\cline { 2 - 2 } & Half area cooling, $120 \mathrm{~L} / \mathrm{h}$ \\
\cline { 2 - 2 } & Full area cooling, $120 \mathrm{~L} / \mathrm{h}$ \\
\hline
\end{tabular}

Table 2. Specification of the PV

\begin{tabular}{|l|r|}
\hline \multicolumn{2}{|c|}{ Technical characteristics } \\
\hline Model & Venus Solar KL-30W-36P \\
\hline Pmax (W) & $30 \mathrm{~W}$ \\
\hline Voc (V) & $21.6 \mathrm{~V}$ \\
\hline Isc (A) & $1.8 \mathrm{~A}$ \\
\hline Vmpp (V) & $17.28 \mathrm{~V}$ \\
\hline Impp (A) & $1.73 \mathrm{~A}$ \\
\hline No. of cells & 36 \\
\hline Effective panel area & $0.173 \mathrm{~m}^{2}$ \\
\hline
\end{tabular}

Fig. 1 shows the testing configurations for different conditions. As shown in Fig. 1, the pipe used on top of the panel has different span of holes to create the half area and full area flow of water. Each hole was drilled with approximately $3 \mathrm{~mm}$ diameter. 


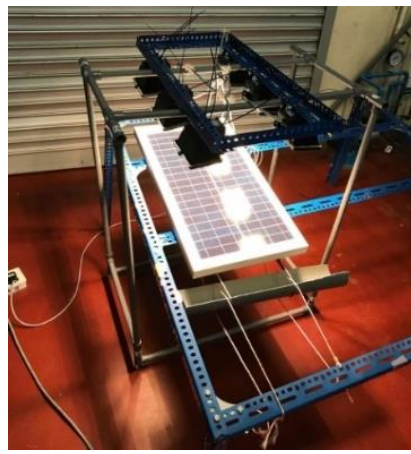

(a) Overall Setup
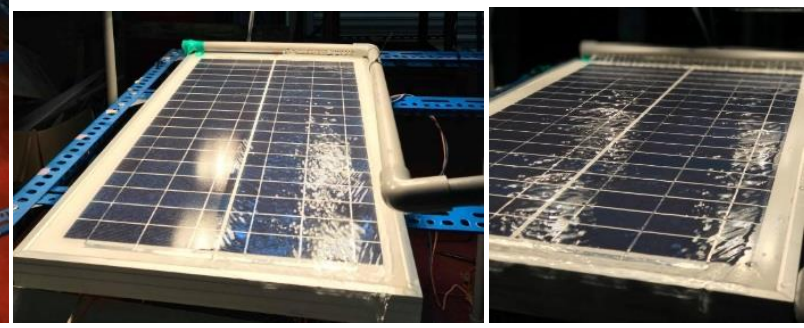

(b) Half surface cooling (c) Full surface cooling

Fig. 1. Testing conditions of the PV

Surrounding air temperature was measured to be in the range between $30^{\circ} \mathrm{C}$ to $33^{\circ} \mathrm{C}$. The initial water inlet temperature was approximately $29^{\circ} \mathrm{C}$ and after each tests ended, it was around $31^{\circ} \mathrm{C}$. To calculate power output and panel efficiency, the following formulas are used.

$$
P=V \times I
$$

where $P$ is the power output calculated in watts (W), $V$ is the instantaneous measured voltage $(\mathrm{V})$, and $I$ is the instantaneous measured current (A).

\section{Results and discussion}

The trend on the temperature, current, voltage and power output of PV at $855 \mathrm{~W} / \mathrm{m}^{2}$ when the PV is cooled and uncooled is shown in Fig.2. For temperature, the panel recorded a maximum temperature of $72.10^{\circ} \mathrm{C}$ when it is uncooled. When it is cooled temperature decreased $22.05 \%$ and $51.04 \%$ for half and full surface, respectively. The temperature also remained constant for full surface around $32^{\circ} \mathrm{C}$. This shows that the reduction of temperature was more than two times when the surface area covered with water was doubled, and it could also maintain the PV at constant temperature.

For the result of current shown in Fig. 2(d), the current remained constant throughout the cooling process in all conditions at $0.58 \mathrm{~A}$. This is as expected because irradiance affects current, but not temperature. Effect of temperature could be seen in voltage as shown in Fig. 2(c). It was found that the trend follows the results of temperature. The non-cooled panel voltage follows the trend of temperature in which it dropped until the voltage was of $16.77 \mathrm{~V}$ at $450 \mathrm{sec}$. Whereas, the panel that received full area cooling could maintain the voltage approximately at $19.0 \mathrm{~V}$ throrughout the experiment. For half cooling, the voltage is between the non-cooled and full area cooling.

As the results, the power outputs for uncooled, half surface, and full surface were $10.38 \mathrm{~W}, 10.66 \mathrm{~W}$ and $11.08 \mathrm{~W}$, respectively. As compared to uncooled, this shows the increment of $6.10 \%$ and $13.50 \%$ for half surface and full surface, respectively. This results is consistent with the results reported by L. Dorobantu that has $9.5 \%$ increase in power output in their PV performance with cooling [9]. 


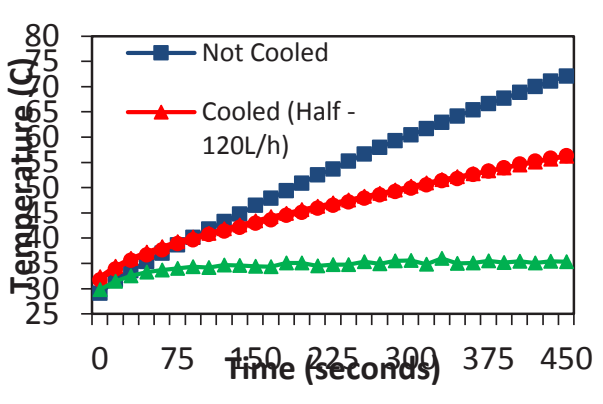

(a) Temperature

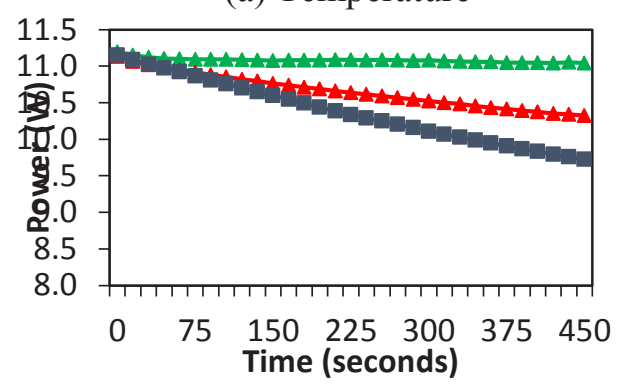

(b) Power

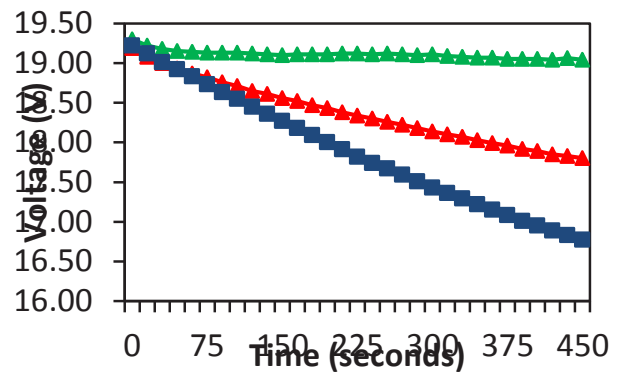

(c) Voltage

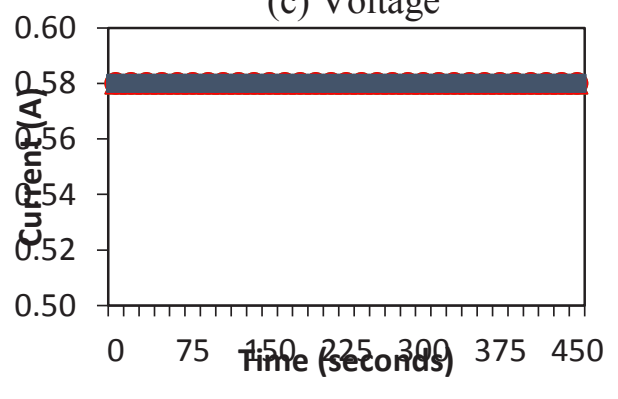

(d) Current

Fig. 2. Results of the PV performance at $855 \mathrm{~W} / \mathrm{m}^{2}$

\section{Conclusion}

Effect of cooling surface area for water-cooled PV was investigated for $50 \%$ and $100 \%$ covered area. It was found that the $50 \%$ of increament of surface area covered could reduce more than $50 \%$ of panel temperature. This reflects power output of the PV in which half surface has $6.1 \%$ increment, whereas full surface has $13.5 \%$ increment. Thus, cooling surface area has substantial effect on the performance of PV. Further study on the performance for different flow rate and irradiance could further understand the phenomenon.

The financial support offered by the Universiti Malaysia Pahang under RDU RDU180313 are gratefully acknowledged

\section{References}

1. I. E. Agency, Snapshot of global photovoltaic markets, (2017).

2. J. Lee, A growing solar industry - Focus, in The Star Online, ed, (2017).

3. A. Kordzadeh, Ren Ene, 35, 1098-1102, (2010).

4. T. K. Ibrahim, F Basrawi, GC Lee, K Habib, H Ibrahim, J. of Sol Ene Engineering, 137, 061009, (2015).

5. L. Y. A Zulkepli, MY Taib, Z Azran, F Basrawi, MATEC Web of Conferences, 29, 02004, (2016).

6. M. A. a. M. Ameri, Ren Ene, 34, 91-96, (2009). 
7. D. Č. S. Nižetić, A. Yadav, and F. Grubišić-Čabo, Ene Conv and Manage, 108, 287-296, (2016).

8. S. Krauter, Sol Ene Mat and Sol Cells, 82, 131-137, (2004).

9. L. D. a. M. O. Popescu, UPB Sci Bul Ser C Elec Eng, 75, 223-232, (2013).

10. M. K. S. et. al., J. of Sol Ene Eng, 136, 034503, (2014).

11. M. S. S. A.-E. K. A. A. Moharram, H. A. A. Kandil, and H. El-Sherif, AinShams Eng, 4, 869-877, (2013).

12. S. O. a. M. Behnia, Heat Trans Eng, 30, 499-505, (2009).

13. Y. M. I. e. al., Energy Procedia, 79, 604-611, (2015). 